\title{
Analysis of the impact of inhomogeneous emissions in the Operational Street Pollution Model (OSPM)
}

\author{
T.-B. Ottosen ${ }^{1,2}$, K. E. Kakosimos ${ }^{1}$, C. Johansson ${ }^{3,5}$, O. Hertel ${ }^{4}$, J. Brandt ${ }^{4}$, H. Skov ${ }^{2,4}$, R. Berkowicz ${ }^{4}$, T. Ellermann ${ }^{4}$, \\ S. S. Jensen ${ }^{4}$, and M. Ketzel ${ }^{4}$ \\ ${ }^{1}$ Department of Chemical Engineering, Texas A\&M University at Qatar, Doha, Qatar \\ ${ }^{2}$ Department of Chemical Engineering, Biotechnology and Environmental Technology, \\ University of Southern Denmark, Odense, Denmark \\ ${ }^{3}$ Department of Environmental Science and Analytical Chemistry, Stockholm University, Stockholm, Sweden \\ ${ }^{4}$ Department of Environmental Science, Aarhus University, Roskilde, Denmark \\ ${ }^{5}$ Environment and Health Administration, Stockholm, Sweden
}

Correspondence to: K. E. Kakosimos (k.kakosimos@qatar.tamu.edu)

Received: 11 December 2014 - Published in Geosci. Model Dev. Discuss.: 4 February 2015

Revised: 3 August 2015 - Accepted: 14 September 2015 - Published: 13 October 2015

\begin{abstract}
Semi-parameterized street canyon models, as e.g. the Operational Street Pollution Model $\left(\right.$ OSPM $\left.^{\circledR}\right)$, have been frequently applied for the last two decades to analyse levels and consequences of air pollution in streets. These models are popular due to their speed and low input requirements. One often-used simplification is the assumption that emissions are homogeneously distributed in the entire length and width of the street canyon. It is thus the aim of the present study to analyse the impact of this assumption by implementing an inhomogeneous emission geometry scheme in OSPM. The homogeneous and the inhomogeneous emission geometry schemes are validated against two real-world cases: Hornsgatan, Stockholm, a sloping street canyon; and Jagtvej, Copenhagen; where the morning rush hour has more traffic on one lane compared to the other. The two cases are supplemented with a theoretical calculation of the impact of street aspect (height / width) ratio and emission inhomogeneity on the concentrations resulting from inhomogeneous emissions. The results show an improved performance for the inhomogeneous emission geometry over the homogeneous emission geometry. Moreover, it is shown that the impact of inhomogeneous emissions is largest for near-parallel wind directions and for high aspect ratio canyons. The results from the real-world cases are however confounded by challenges estimating the emissions accurately.
\end{abstract}

\section{Introduction}

Semi-parameterized models as e.g. the Operational Street Pollution Model (OSPM ${ }^{\circledR}$; Berkowicz et al., 1997) have been frequently applied in cities around the globe over the last 20 years (Assael et al., 2008; Berkowicz et al., 1996, 2006; Ghenu et al., 2008; Gokhale et al., 2005; Hertel et al., 2008; Kakosimos et al., 2010; Ketzel et al., 2012; Kukkonen et al., 2000; Vardoulakis et al., 2005). This type of model has the advantages of low input requirements and short execution times. This means that the model can cover many streets over long time periods due to its low computational demand.

In order to retain the low calculation time of these models, a number of simplifying assumptions have to be made. One assumption, present in e.g. OSPM, is that the emissions are distributed homogeneously over the street canyon in the full length and width of the canyon. However, real streets have traffic lanes with finite width and varying traffic loads, either permanently or as a function of time as e.g. rush hours. Moreover, they might have sidewalks or cycle lanes with no emissions or wide central reserves likewise without emissions. Modelling these situations as homogeneous emission will potentially overestimate one side of the street and underestimate the other side of the street. This has an influence on e.g. limit values, where one side of the street can exceed the limit value while the other does not. 
Sloping streets represent a natural case of inhomogeneous emissions in that vehicles driving uphill have a higher emission due to the increased engine load compared to vehicles driving downhill. Gidhagen et al. (2004) examined the measured $\mathrm{NO}_{x}$ concentrations from a measurement campaign in Hornsgatan in Stockholm, Sweden, which has a slope of $2.3 \%$, using a computational fluid dynamics (CFD) model. It was shown that the model representation of the wind direction dependence of the concentrations compared to the wind direction dependence of the measurements improved by assuming an emission relationship of $3: 1$ between the uphill and downhill side of the road. This followed along a marginal improvement in the correlation between the model and the measurements. In Gidhagen et al. (2004), Kean et al. (2003) is also quoted for reporting markedly higher emissions for vehicles going uphill compared to vehicles going downhill, a feature also implemented in emission models like the Handbook Emission Factors for Road Transport HBEFA (www.hbefa.net).

Moreover, Kakosimos et al. (2010) and Vardoulakis et al. (2007) suggested that an improvement in the applicability of semi-empirical street level air quality models could be achieved by implementation of an inhomogeneous emission geometry scheme.

The present study is therefore based on the following research question:

To what extend do the performance of street pollution models like OSPM improve as a result of moving from homogeneous emissions to inhomogeneous emissions, and how is this change influenced by the aspect ratio of the street and the inhomogeneity of the emissions?

The methods applied in the present study are explained in Sect. 2. This is followed by a description of how the concentrations are calculated based on respectively the homogeneous and the inhomogeneous emissions in Sect. 3. The results and discussion are placed in Sect. 4 and the conclusions are presented in Sect. 5.

\section{Methods}

To analyse the impact of inhomogeneous emissions in OSPM two real-world cases were selected as being representative for inhomogeneous emission geometry streets as found in urban areas. The two real-world cases were supplemented by a set of theoretical calculations to analyse the impact of inhomogeneity and aspect ratio on the results.

The two street canyons chosen to analyse the impact of inhomogeneous emissions were respectively Hornsgatan in Stockholm, Sweden, and Jagtvej in Copenhagen, Denmark. The main characteristics of the two street canyons are summed up in Table 1. Hornsgatan is an example of a sloping street canyon with the average slope being $2.3 \%$ (Gidhagen et al., 2004), and Jagtvej is diurnally inhomogeneous in that, depending on the time of day, there is more traffic in the northeast direction compared to the southwest direction. Both streets have two driving lanes in each direction (four lanes in total) plus non-emitting areas at the sides. The non-emitting areas are however not modelled explicitly in the present analysis, since including this would require the implementation of horizontal diffusion in the model, cf. the discussion in Sect.3.2. This task remains for future work.

In the analysis, the $\mathrm{NO}_{x}$ concentrations were used since in OSPM the concentration of $\mathrm{NO}_{2}$ is calculated based on the concentration of $\mathrm{NO}_{x}$ and $\mathrm{O}_{3}$. Thus, in order not to add the uncertainties from the chemistry in the analysis, the primary emitted tracer $\left(\mathrm{NO}_{x}\right)$ is used. Moreover, previous studies (Ketzel et al., 2011, 2012) have shown that the emission and dispersion module implemented in OSPM have an acceptable performance for this species.

The years 2007-2009 were chosen for Hornsgatan given that the use of studded tires has been banned on this street since 2010, which probably affected the vehicle distribution. Modelling the influence of this was assessed to be complicated and outside the scope of the present study. For Jagtvej, the years 2003 and 2013 were chosen since traffic counts were performed next to the measurement station in these years. In order to assess the influence of inhomogeneous emissions, accurate traffic input is very important.

Both streets are part of routine air quality control monitoring programs and have been studied extensively in the past. One year of data from Hornsgatan were included in the Street Emission Ceiling exercise (Larssen et al., 2007; Moussiopoulos et al., 2005, 2004) and has thus been subject of a number of modelling studies (e.g. Denby et al., 2013a, b; Johansson et al., 2009; Ketzel et al., 2007; Olivares et al., 2007). The Jagtvej measurement station is part of the Danish air quality monitoring programme (Ellermann et al., 2013) and has likewise been the subject of extensive analysis (e.g. Ketzel et al., 2011, 2012; Silver et al., 2013).

\subsection{Emission modelling and measurements from Hornsgatan}

The emission modelling for Hornsgatan uses the hourly automatic vehicle counts for the two driving directions on Hornsgatan. The vehicle counts were made using an inductive loop technology (Marksman 660 Traffic Counter and Classifier, Golden River Traffic Ltd, UK). It provides hourly mean total traffic counts, classification of vehicles based on the length of the vehicle, plus mean speed on a lane by lane basis. The automatic counts in the east inner lane were multiplied by 4.2 to compensate for a bias in the counting based on a manual counting check. The exact technical reason for this factor is not known. However, comparisons between the Marksman counter and manual counts and between the Marksman counter and automatic camera recordings (Burman and Johansson, 2010) have confirmed the validity of this factor.

The vehicle distribution was modelled as the average weekly vehicle distribution based on vehicle classifications 
Table 1. Overview of the properties of the two street canyons used for validation of the dispersion schemes in the study. There is a measurement station (receptor) at each side of the street in Hornsgatan, but only one measurement station on the east side of Jagtvej.

\begin{tabular}{|c|c|c|}
\hline Name & Hornsgatan & Jagtvej \\
\hline City & Stockholm & Copenhagen \\
\hline Country & Sweden & Denmark \\
\hline Latitude & $59^{\circ} \mathrm{N}$ & $55^{\circ} \mathrm{N}$ \\
\hline Width & $24 \mathrm{~m}$ & $25 \mathrm{~m}$ \\
\hline Height & $24 \mathrm{~m}$ & $22 \mathrm{~m}$ \\
\hline Years in analysis & 2007, 2008, 2009 & 2003, 2013 \\
\hline Street orientation & $76^{\circ}$ & $30^{\circ}$ \\
\hline Average daily traffic & 35500 & 20000 \\
\hline Mean vehicle speed $\left(\mathrm{km} \mathrm{h}^{-1}\right)$ & 45 & 29 \\
\hline Heavy duty share & $4 \%$ & $3 \%$ \\
\hline Receptor height & $3.0 \mathrm{~m}$ (north) $3.3 \mathrm{~m}$ (south) & $3.6 \mathrm{~m}$ (east) \\
\hline
\end{tabular}

obtained by video number plate recognition in the fall of 2009 (Burman and Johansson, 2010). This ensured that the emission factors reflected the average weekly variation in vehicle distribution. All vehicle categories were modelled using HBEFA 3.2 (www.hbefa.net) except ethanol buses, which do not appear as a vehicle category in HBEFA. These were instead modelled using the ARTEMIS (Assessment of Road Transport Emission Models and Inventory Systems) emission model (Boulter and McCrae, 2007). The emission factors from ARTEMIS were scaled to a different set of velocities compared to HBEFA. In order to scale the two emission models, the emissions from ARTEMIS were linearly interpolated to match the travel speeds from HBEFA.

The emission factors from HBEFA version 3.2, were used for the emission modelling since this emission model includes the effect of slope on the emissions. The emissions were exported from this model for slopes of \pm 2 and $\pm 4 \%$ and a linear interpolation to the slope of $\pm 2.3 \%$, as given by Gidhagen et al. (2004), was performed. In Gidhagen et al. (2004), the Tehran Emission Reduction Project is cited for reporting uphill emissions being 3-4 times larger than downhill emissions. A significant emission difference between the north and south side of the street can therefore be expected.

The traffic flow situation (called "level of service" in HBEFA) was modelled as a set of discrete categories. This was done by categorising the individual hour based on the total number of vehicles in the hour. The categorisation was performed based on the scheme from the ARTEMIS model reprinted in Table 2.

In setting up OSPM, the street was divided into two emission segments of equal width, each segment covering two traffic lanes, although the inhomogeneous emission scheme described in Sect. 3.2 allows for any number of segments. The emissions were distributed over both the lanes and the sidewalk since the modelling of sidewalks is not yet a feature of the model, cf. the discussion in Sect. 3.2. The vehicle speed, used for the calculation of traffic-produced turbulence,
Table 2. Level of service as a function of total number of vehicles per hour based on Vägverket and SMHI (2007).

\begin{tabular}{ll}
\hline $\begin{array}{l}\text { Level of } \\
\text { service }\end{array}$ & $\begin{array}{l}\text { Total number of } \\
\text { vehicles per hour }\end{array}$ \\
\hline Free flow & $<601$ \\
Heavy & $601-899$ \\
Saturated & $900-1399$ \\
Stop + go & $>1400$ \\
\hline
\end{tabular}

was assumed equal to the mean speed between the two lanes comprising the segment.

The emission modelling for Hornsgatan was performed based on two approaches.

- An approach based on the hypothesis that the traffic on the individual lane can be modelled as half the total traffic, subsequently referred to as the "proportional" approach. The inhomogeneity thus only arises from the slope of the street. This approach is useful if directionalor lane-divided traffic counts do not exist for the street in question.

- An approach based on the modelling of inhomogeneous emissions based on traffic counts from the individual lane as described above. This approach is subsequently referred to as the "exact" approach.

The two approaches to emission modelling were subsequently compared.

$\mathrm{NO}_{x}$ was simultaneously monitored on the northern and southern sides of the road with a commercial $\mathrm{NO}_{x}$ chemiluminescence analyser (model $31 \mathrm{M} \mathrm{LCD}$, Environment SA, France). Urban background concentrations were taken from an identical instrument at a monitoring station located on the roof of a building approx. 500 m east of the Hornsgatan street station. The roof level station is representative of the urban 
background and is not influenced by the emissions in any nearby street canyon.

To analyse if the emissions distribution between the north side and the south side of the street can be modelled as a constant ratio, an analysis of measurements for near-parallel $\left( \pm 30^{\circ}\right)$ wind directions for the conditions of a minimum wind speed of $2 \mathrm{~m} \mathrm{~s}^{-1}$ was performed. It was hypothesised that the ratio between the measured concentrations corresponds to the proportions between the emissions. This assumption is of course violated as a result of horizontal dispersion in the street canyon, but this effect was disregarded.

As seen in Fig. 1, the distribution of concentration ratios between the northern and southern sides of the street is skewed with the mode being around 1.2 and the mean value being 3.2. This result is not too far from the result presented by Gidhagen et al. (2004), where the emissions on the north side were 3 times as large as on the south side. Moreover, the distribution is unimodal and has a relatively low standard deviation, which supports the assumption of an even traffic distribution between the north side and the south side of the street.

The hypothesis of a constant ratio distribution will be fortified if the ratio is not changing systematically with time.

The diurnal and weekly variation of the ratio is shown in Fig. 2. As can be seen, the values show no clear diurnal or weekly variation and thus the assumption of an even distribution of traffic, but inhomogeneous emissions due to the slope in the two directions, between the two segments seems valid.

\subsection{Emission modelling and measurements from Jagtvej}

Manual traffic counts next to the measurement station at Jagtvej were performed respectively in 2003 and in 2013. The traffic was counted in two directions on a weekday for 24h in 2003 and between 07:00 and 19:00 LT in 2013. The number of vehicles was split into a number of vehicle classes to provide the vehicle distribution. The emissions were modelled using the COPERT 4 model (COmputer Programme to calculate Emissions from Road Transport; EEA, 2009).

The diurnal vehicle speed profile for Jagtvej was based on a national study aiming to establish typical diurnal speed profiles for different types of urban streets (TetraPlan A/S, 2001) where the most representative for Jagtvej was chosen. Furthermore, average travel speed data were obtained from a recent national data set (http://speedmap.dk/portal) managed by the Danish Road Directorate. SpeedMap is based on GPS readings from vehicle fleets and provides travel speeds on all major roads in Denmark in a high spatial and temporal resolution. The average vehicle speed from 2011 was used to scale the diurnal profiles from the original study, and the velocity profile was assumed valid for both 2003 and 2013 since no information on the temporal development in vehicle speeds were available within the limits of the present study.

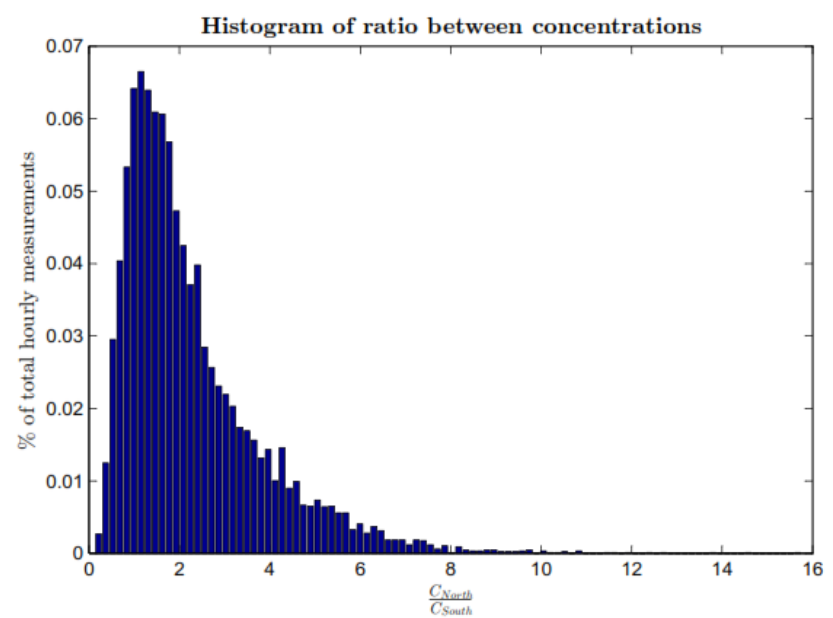

Figure 1. Histogram of ratio between the north side and south side receptors for near-parallel wind directions for Hornsgatan, Stockholm.

The emissions were subsequently distributed in two segments, each covering half of the street width; thus, both covering the traffic lanes and the sidewalks. The choice of two segments was made since the traffic counts were only distributed into driving directions and not on the individual lane.

The $\mathrm{NO}_{x}$ measurements at the east side of Jagtvej were performed continuously by chemiluminescence using $\mathrm{NO}_{x}$ Aerodyne API (Atmospheric Pressure Interface) instruments. The urban background measurements were measured from a roof level measurement station approximately $500 \mathrm{~m}$ from the street using similar instrumentation as the street level measurements.

\subsection{Theoretical calculations}

The resulting concentrations of inhomogeneous emissions as a function of street aspect ratio and emission inhomogeneity were calculated for 360 wind directions with wind speed and total emissions approximately similar to the average conditions for Hornsgatan in order to generate comparable results. The calculations were performed on a hypothetical street canyon with two emission segments each covering half the width of the street. Subsequently, the aspect ratio and the emission inhomogeneity were varied over a reasonable interval.

\section{Model description}

In the following sections, the currently applied homogeneous and the tested inhomogeneous emission dispersion schemes will be described. This section does not contain a complete description of the OSPM model, for this the reader is referred to e.g. Berkowicz et al. (1997). However, sufficient details 

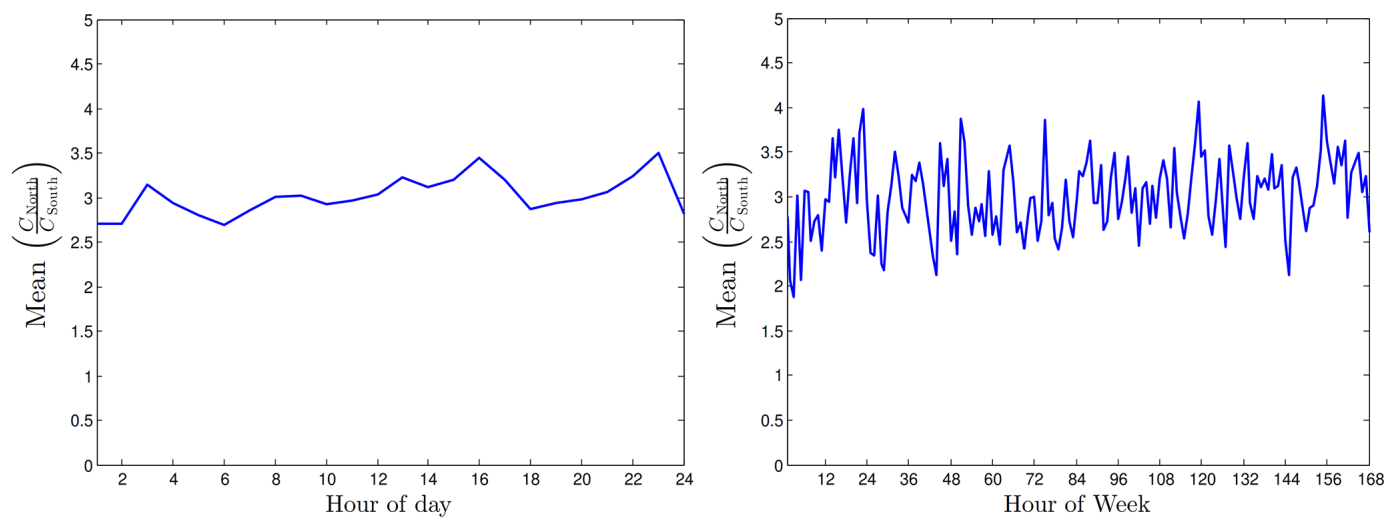

Figure 2. Diurnal and weekly variation in the mean ratio between the concentrations for the north side and south side receptors for nearparallel wind directions with wind speeds above $2 \mathrm{~m} \mathrm{~s}^{-1}$ for Hornsgatan, Stockholm.

will be provided to understand the modifications in the model regarding handling the emission geometry.

\subsection{The homogeneous emission dispersion scheme}

To illustrate the modelling principles of OSPM, a typical street canyon situation is illustrated in Fig. 3. OSPM calculates the concentrations $(C)$ at the wall side of the street canyon as a contribution from the street canyon $\left(C_{\text {street }}\right)$ plus a contribution from urban background concentrations $\left(C_{\mathrm{bg}}\right)$. The contribution from the street canyon is subsequently a sum of a direct contribution $\left(C_{\mathrm{dir}}\right)$ plus a recirculating contribution $\left(C_{\text {rec }}\right)$ (Berkowicz et al., 1997):

$C=C_{\text {street }}+C_{\mathrm{bg}}$,

$C_{\text {street }}=C_{\text {dir }}+C_{\text {rec }}$.

It is a fundamental assumption of the model that when the wind blows over a rooftop in a street canyon an hourly averaged recirculation vortex is always formed inside the canyon as illustrated in Fig. 3.

It is assumed that the ground level wind direction inside the recirculation zone is mirrored compared with the roof level wind direction, whereas outside the recirculation zone the wind direction follows the roof level wind direction as illustrated in Fig. 4.

The receptor at the leeward (1) side of the canyon is thus exposed both to a direct contribution from emissions inside the recirculation zone (unless the wind direction is close to parallel as described in Sect. 3.1.1) and a recirculating contribution, and the windward receptor (2) is exposed to a direct contribution from emissions outside the recirculation zone (Berkowicz et al., 1997) and to diluted recirculating emissions from inside the recirculation zone (Ketzel et al., 2014). In the case where the recirculation zone occupies the whole street canyon, the leeward (marked with "1" in Fig. 5) side of the canyon will be exposed to both a direct and a recirculating contribution, whereas the windward receptor (marked

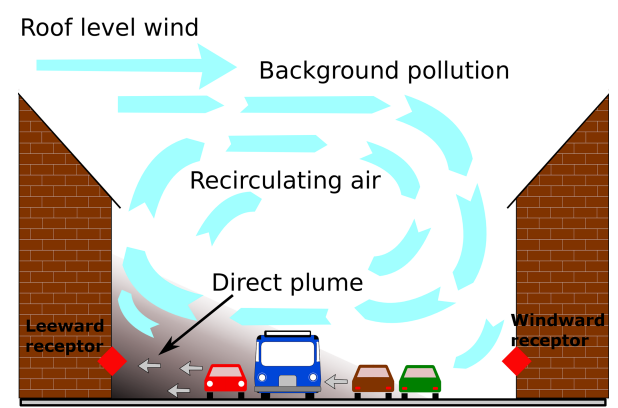

Figure 3. Cross section of a street canyon. The figure illustrates the governing flow patterns as modelled in OSPM. The two receptors are marked with red diamonds. In the figure the recirculation zone occupies the whole canyon although this need not be the case as e.g. shown in the following figures. Figure modified from Silver et al. (2013).

with "2" in Fig. 5) will only be influenced by the recirculating contribution.

\subsubsection{The direct contribution}

The direct contribution can be written in integral form as (Hertel and Berkowicz, 1989)

$\int_{x_{\text {start }}}^{x_{\text {end }}} \frac{\mathrm{d} C_{\mathrm{dir}}}{\mathrm{d} x} \mathrm{~d} x=\sqrt{\frac{2}{\pi}} \frac{Q}{W \sigma_{\mathrm{w}}} \int_{x_{\text {start }}}^{x_{\text {end }}} \frac{1}{x+\frac{u_{\text {stree }} h_{0}}{\sigma_{\mathrm{w}}}} \mathrm{d} x$,

where $C_{\mathrm{dir}}$ is the direct contribution; $x_{\text {start }}$ is the distance from the receptor where the plume has the same height as the receptor, which can also be zero in case $h_{\mathrm{r}} \leq h_{0} ; x_{\text {end }}$ is the upper integration limit as defined in Table $3 ; h_{0}$ is the height of the plume in the wake of a car (usually termed the "initial dispersion"); $h_{\mathrm{r}}$ is the height of the receptor (the height of the calculated concentration); $Q$ is the emission flux (in $\left.\mathrm{g} \mathrm{m}^{-1} \mathrm{~s}^{-1}\right) ; W$ is the width of the street; $u_{\text {street }}$ is the street level wind speed; and $\sigma_{\mathrm{w}}$ is the vertical turbulence flux cal- 


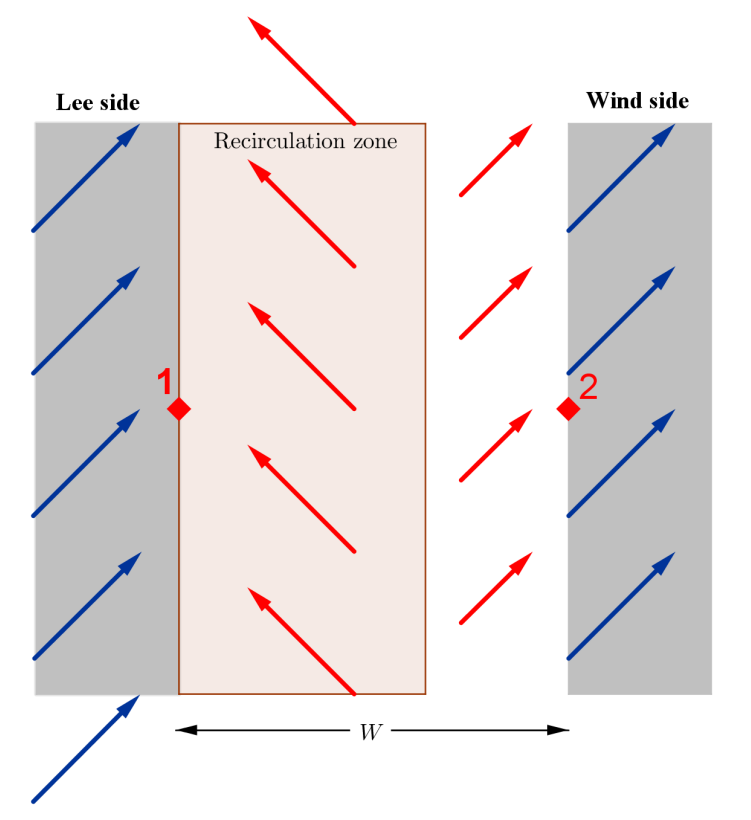

Figure 4. Schematic view of a street canyon seen from the top. The arrows represent the wind directions as modelled in OSPM. The length of the arrows are not proportional to the wind speed. The blue arrows are rooftop wind directions and the red arrows are street level wind directions. The receptors are marked with red diamonds.

culated as a function of the street level wind speed and the traffic produced turbulence.

The integration is performed along a straight line path against the wind direction as illustrated in Fig. 5. Equation (3) is used for calculating the direct contribution on both the leeward side and the windward side; however, the length of the integration paths can differ likewise as illustrated in Fig. 5.

In Fig. 5 it is assumed that $x_{\text {end }}=L_{\text {rec }}$, the length of the recirculation zone; however, as shown in Table 3 this needs not be the case. The calculation of $L_{\mathrm{rec}}$ as a function of the upwind building height $\left(H_{\mathrm{u}}\right)$ and the shortening function $\left(f_{\text {red }}\right)$ is defined in Table 4.

For very long street canyons the plume will start dispersing out of the canyon at the top. In OSPM, this is assumed to happen when the plume height $\left(\sigma_{z}\right)$ equals the general building height $\left(H_{\mathrm{g}}\right)$ (Ketzel et al., 2014) of the canyon. This point is called $x_{\text {esc }}$ and is defined as (Hertel and Berkowicz, 1989)

$x_{\mathrm{esc}}=\frac{u_{\text {street }}\left(H_{\mathrm{g}}-h_{0}\right)}{\sigma_{\mathrm{w}}}$.

Beyond the point $x_{\mathrm{esc}}$, the contribution to the concentration at the receptor is assumed to decay exponentially with distance according to (Hertel and Berkowicz, 1989)

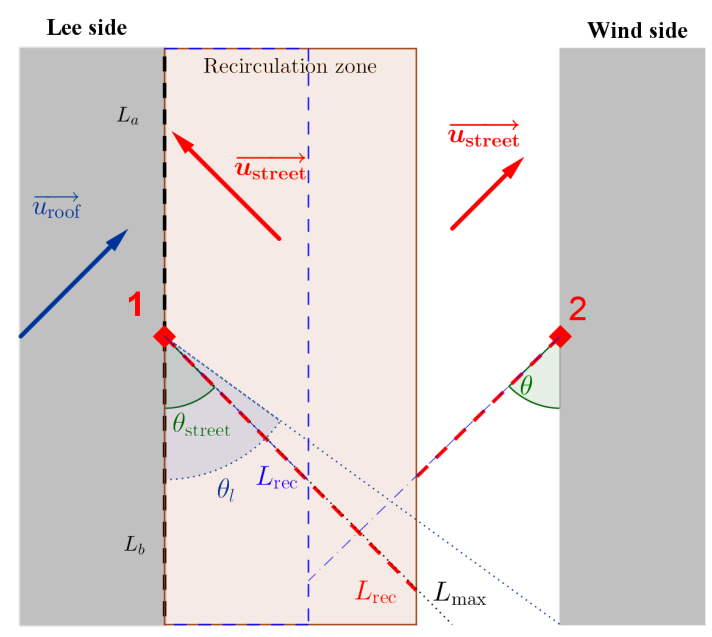

Figure 5. Illustration of the integration paths (red dotted lines) for an arbitrary wind direction for the two receptors in the canyon. The upper blue dotted line marks a critical wind direction $\left(\theta_{l}\right)$ which affects the calculation of the integration path length, and $L_{b}$ is the length to the end of the canyon used to calculate the maximum integration length $\left(L_{\max }\right) . L_{\text {rec }}$ is the length of the recirculation zone. A second recirculation zone is illustrated in blue with the new integration lengths likewise plotted with dotted blue lines.

Table 3. Table of upper integration limits for respectively Eq. (3) $\left(x_{\text {end }}\right)$ and Eq. (5) $\left(x_{\text {end }}^{\prime}\right)$. The definition and calculation of the lengths can be found in Table 4.

\begin{tabular}{lll}
\hline Magnitude & $x_{\text {end }}$ & $x_{\text {end }}^{\prime}$ \\
\hline$L_{\text {rec }}>x_{\text {esc }}>L_{\text {max }}$ & $L_{\max }$ & - \\
$L_{\text {rec }}>L_{\max }>x_{\text {esc }}$ & $x_{\text {esc }}$ & $L_{\max }$ \\
$x_{\mathrm{esc}}>L_{\text {rec }}>L_{\text {max }}$ & $L_{\max }$ & - \\
$x_{\text {esc }}>L_{\max }>L_{\text {rec }}$ & $L_{\text {rec }}$ & - \\
$L_{\max }>x_{\text {esc }}>L_{\text {rec }}$ & $L_{\text {rec }}$ & - \\
$L_{\max }>L_{\text {rec }}>x_{\text {esc }}$ & $x_{\text {esc }}$ & $L_{\text {rec }}$ \\
\hline
\end{tabular}

$\int_{x_{\text {esc }}}^{x_{\text {end }}^{\prime}} \frac{\mathrm{d} c_{\mathrm{dir}}}{\mathrm{d} x} \mathrm{~d} x=\sqrt{\frac{2}{\pi}} \int_{x_{\mathrm{esc}}}^{x_{\text {end }}^{\prime}} \frac{Q}{u_{\text {street }} W H_{\mathrm{g}}} e^{-\frac{\sigma_{\mathrm{wt}}}{H_{\mathrm{g}} u_{\text {street }}}\left(x-x_{\text {esc }}\right)} \mathrm{d} x$,

where $\sigma_{\mathrm{wt}}$ is the roof level turbulence, and $x_{\text {end }}^{\prime}$ is the upper limit of the integral as defined in Table 3 . The calculations and definitions of the critical lengths $x_{\text {start }}, L_{\text {rec }}$, and $L_{\max }$ are summed up in Table 4.

For close to parallel wind directions the integration length $\left(x_{\text {end }}\right)$ for the leeward side receptor (1) is extended from $L_{\text {rec }}$ to $L_{\max }$ to account for concentrations resulting from emissions outside the recirculation zone. The calculation of $L_{\max }$ as a function of the street width $(W)$, the wind direction with respect to the street axis $\left(\theta_{\text {street }}\right)$, and the length to the end of the canyon is defined in Table 4 . The integration is extended when $\theta_{\text {street }}$ is smaller than $45^{\circ}$, and the contribution to the 
Table 4. Table of the critical lengths along the integration path. These lengths determine the upper and lower limits of the integrals in the homogeneous emission dispersion scheme and of the sums in the inhomogeneous emission dispersion scheme. Moreover, they determine if the dispersion should be calculated according to Eqs. (3) or (5) plus whether the concentration should be multiplied with $f_{\text {ext }}$ as defined in Eq. (6). $f_{\text {red }}$ is the shortening function as defined in Eq. (6), $H_{\mathrm{u}}$ is the upwind building height, $\theta_{\text {street }}$ is the wind direction compared to the street direction, $\theta_{l}$ is the critical wind direction as illustrated in Fig. 5, $W$ is the street width, $L_{b}$ is the length from the receptor to the end of the street as illustrated in Fig. 5, and $h_{\mathrm{r}}$ is the height of the inlet of the receptor above street level.

\begin{tabular}{lllll}
\hline Name & \multicolumn{2}{c}{ Expression } & Description \\
\hline$L_{\text {rec }}$ & \multicolumn{2}{c}{$2 \cdot f_{\text {red }} \cdot H_{\mathrm{u}}$} & Length of the recirculation zone \\
\hline \multirow{2}{*}{$x_{\text {start }}$} & $\frac{u_{\text {street }}\left(h_{\mathrm{r}}-h_{0}\right)}{\sigma_{\mathrm{w}}}$ & $; \quad h_{\mathrm{r}}>h_{0}$ & Length where the vertical dispersion of the plume equals the height of the receptor \\
& 0 & $;$ & $h_{\mathrm{r}} \leq h_{0}$ & \\
\hline$L_{\max }$ & $\frac{W}{\sin \left(\theta_{\text {street }}\right)}$ & $;$ & $\theta_{\text {street }}>\theta_{l}$ & Maximum integration path length \\
& $\frac{L_{b}}{\cos \left(\theta_{\text {street }}\right)}$ & $;$ & $\theta_{\text {street }}<\theta_{l}$ & \\
\hline
\end{tabular}

concentrations from the path outside the recirculation zone is then multiplied by $f_{\text {ext }}(\text { Hertel and Berkowicz, 1989) })^{1}$ :

$f_{\text {ext }}=\cos \left(2 f_{\text {red }} \theta_{\text {street }}\right)$

$f_{\text {red }}=\left\{\begin{array}{ccc}1 & ; & u_{\text {street }}>2 \mathrm{~m} \mathrm{~s}^{-1} \\ \sqrt{0.5 u_{\text {street }}} & ; & u_{\text {street }}<2 \mathrm{~m} \mathrm{~s}^{-1}\end{array}\right.$,

where $\theta_{\text {street }}$ is the angle between the street and the street level wind direction.

\subsubsection{The recirculating contribution}

The recirculating contribution is parameterized as a box model, where it is assumed that the inflow of pollutants equals the outflow of pollutants as illustrated in Fig. 6.

The inflow of pollutants is the emission density in the street multiplied by the integration length $L_{\text {base }}$ (Berkowicz et al., 1997):

$Q_{\text {in }}=\frac{Q}{W} L_{\text {base }}$,

where $L_{\text {base }}=\min \left(L_{\text {rec }}, L_{\max }\right)$. The recirculation zone is modelled as a trapezium with the upper length being half of the baseline length. The outflow from the box model is thus the ventilation at the top of the recirculation trapezium $\left(\sigma_{\mathrm{wt}} L_{\mathrm{top}}\right)$ plus the ventilation at the hypotenuse of the trapezium $\left(\sigma_{\text {hyp }} L_{\text {hyp }}\right)$ as illustrated in Fig. 6 (Berkowicz et al., 1997):

$Q_{\text {out }}=C_{\text {rec }}\left(\sigma_{\mathrm{wt}} L_{\mathrm{top}}+\sigma_{\mathrm{hyp}} L_{\mathrm{hyp}}\right)$,

where $C_{\text {rec }}$ is the recirculating concentration contribution and $\sigma_{\text {hyp }}$ is the average turbulence at the hypotenuse. Equations (7) and (8) can now be solved for the recirculating concentration by setting the inflow equal to the outflow:

$C_{\text {rec }}=\frac{\frac{Q}{W} L_{\text {base }}}{\sigma_{\mathrm{wt}} L_{\mathrm{top}}+\sigma_{\mathrm{hyp}} L_{\mathrm{hyp}}}$.

\footnotetext{
${ }^{1}$ In Hertel and Berkowicz (1989) $f_{\text {red }}$ is defined as $f_{\text {red }}=$ $0.5 u_{\text {street }}$ for $u_{\text {street }}<2 \mathrm{~m} \mathrm{~s}^{-1}$. This has subsequently been changed to $f_{\text {red }}=\sqrt{0.5 u_{\text {street }}}$ for $u_{\text {street }}<2 \mathrm{~m} \mathrm{~s}^{-1}$.
}

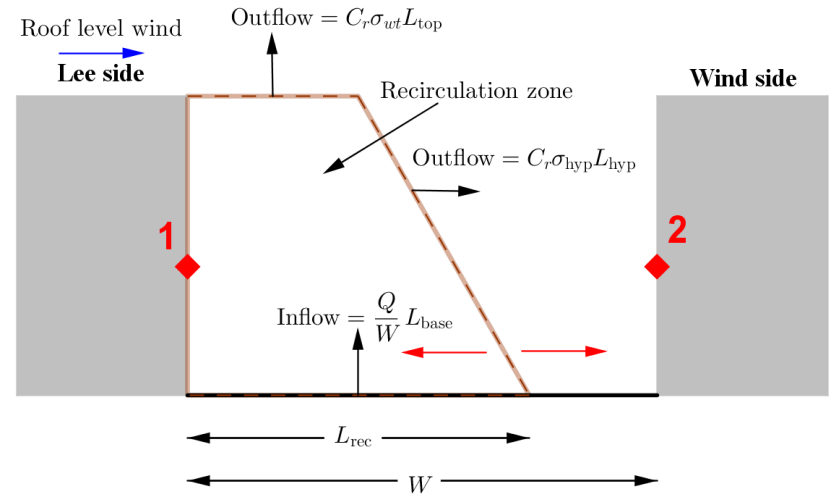

Figure 6. Cross section of a street canyon with the dimensions of the recirculation zone illustrated. The red arrows represent the street level wind direction. Based on Hertel and Berkowicz (1989, p. 69).

\subsubsection{Summarising the dispersion module in OSPM}

For regular street canyons (height to width ratio close to one) the recirculation zone will occupy the majority of the canyon. This means that, for a large wind direction interval, the integration length for the leeward receptor will be significantly longer than the integration length for the windward receptor. Furthermore, the leeward receptor will be exposed to the full recirculating contribution, while the windward receptor only receives a further diluted recirculating contribution. These two effects mean that the leeward receptor will experience significantly higher concentrations than the windward receptor for a large wind direction interval.

\subsection{The inhomogeneous emission dispersion scheme}

In order to facilitate the modelling of streets with inhomogeneous emission distributions, the street was divided into a number of parallel segments as illustrated in Fig. 7. The 
Table 5. Correlation coefficient, fractional bias, and normalised mean square error for the years 2007-2009 for the north side receptor. "Exact" and "Proportional" refer to the emission modelling approaches described in Sect. 2.1. Moreover, the measured and modelled annual mean $\mathrm{NO}_{x}$ concentrations for the individual years are also shown. These are calculated as local street contribution only i.e. the background concentration subtracted from the measured/modelled street concentration to reflect the street contribution.

\begin{tabular}{lrrrr}
\hline & & & \multicolumn{2}{c}{ Inhomogeneous emissions } \\
\cline { 3 - 4 } & Measured & $\begin{array}{r}\text { Homogeneous } \\
\text { emissions }\end{array}$ & Exact & Proportional \\
\hline Correlation coefficient $\left(R^{2}\right)$ & 0.85 & 0.85 & 0.85 \\
Fractional bias (FB) & -0.30 & -0.16 & -0.17 \\
Normalised mean square error (NMSE) & & 0.36 & 0.26 & 0.26 \\
Annual mean 2007 (ppb) $(\Delta C)$ & 56.8 & 44.3 & 53.0 & 51.3 \\
Annual mean 2008 $(\mathrm{ppb})(\Delta C)$ & 53.9 & 37.7 & 44.2 & 44.2 \\
Annual mean 2009 $(\mathrm{ppb})(\Delta C)$ & 53.9 & 35.0 & 40.5 & 40.2 \\
\hline
\end{tabular}

model user will define the width and the emission strength of each segment. At runtime the model calculates several distances (e.g. $\left.L_{\mathrm{rec}}, x_{\mathrm{esc}}\right)$ that depend on the wind flow conditions. The user-defined emission segments are subsequently split into one or more segments with constant emission at these distances. To calculate the concentration from the userdefined and flow-generated segments, the above mentioned integrals become divided into a number of integrals and subsequently summed to yield the final concentration. The direct contribution thus becomes

$$
\begin{aligned}
& \int_{x_{\text {start }}}^{x_{\text {end }}} \frac{\mathrm{d} c_{\mathrm{dir}}}{\mathrm{d} x} \mathrm{~d} x= \\
& \sqrt{\frac{2}{\pi}} \frac{1}{\sigma_{\mathrm{w}}} \sum_{i=n_{\text {start }}}^{n_{\text {end }}} \frac{Q_{i}}{W_{i}-W_{i-1}} \int_{W_{i-1}^{\prime}}^{W_{i}^{\prime}} \frac{1}{x+\frac{u_{\text {street }} h_{0}}{\sigma_{\mathrm{w}}}} \mathrm{d} x,
\end{aligned}
$$

where $n_{\text {end }}$ is the segment number of the last segment influencing the receptor, $n_{\text {start }}$ is the first segment to influence the concentration at the receptor, $W_{i}$ is the accumulated width of the segment calculated from the receptor, and $W_{i}^{\prime}$ is the accumulated width of the segment calculated along the integration path from the receptor. The segments defined by $W_{i}$ and $W_{i}^{\prime}$ can be either user-defined or dynamically generated.

The exponentially decaying concentration contribution from segments further away than $x_{\text {esc }}$ from the receptor becomes

$$
\begin{aligned}
& \int_{x_{\mathrm{esc}}}^{x_{\text {end }}^{\prime}} \frac{\mathrm{d} c_{\mathrm{dir}}}{\mathrm{d} x} \mathrm{~d} x=\sqrt{\frac{2}{\pi}} \sum_{i=n_{\text {start }}}^{n_{\text {end }}} \frac{Q_{i}}{u_{\text {street }}\left(W_{i}-W_{i-1}\right) H} \\
& \int_{W_{i-1}^{\prime}}^{W_{i}^{\prime}} e^{-\frac{\sigma_{\mathrm{wt}}}{H u_{\text {street }}}\left(x-x_{\mathrm{esc}}\right)} \mathrm{d} x .
\end{aligned}
$$

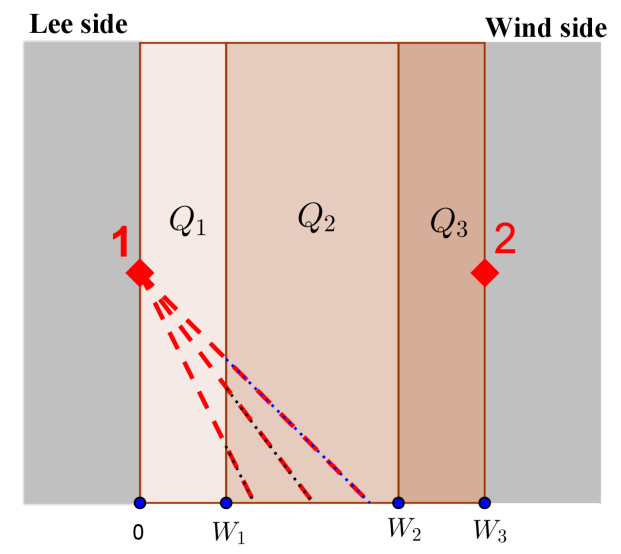

Figure 7. Illustration of the division of the street canyon into a number of segments with accumulated widths $W_{1}, W_{2}, W_{3}$, etc. and emission strengths $Q_{1}, Q_{2}, Q_{3}$, etc. The red dotted lines represent the integration path for receptor 1 for different wind directions. The blue dotted lines represent the contribution from segment $Q_{2}$.

The recirculating contribution becomes

$$
\begin{aligned}
& C_{\mathrm{rec}}=\frac{1}{\sigma_{\mathrm{wt}} L_{\mathrm{top}}+\sigma_{\mathrm{hyp}} L_{\mathrm{hyp}}} \\
& \sum_{i=n_{\mathrm{start}}}^{n_{\mathrm{end}}} \frac{Q_{i}}{W_{i}-W_{i-1}}\left(W_{i}^{\prime}-W_{i-1}^{\prime}\right) .
\end{aligned}
$$

In the homogeneous emission scheme the limits of the integrals are determined by the street geometry and the recirculation zone geometry. In the inhomogeneous scheme the limits of the integrals are always $W_{i-1}^{\prime}$ and $W_{i}^{\prime}$, whereby, instead, the limits of the sum determine which segments contribute to the concentration at the receptor.

As seen from the lack of $y$ dependence in Eqs. (3) and (10), the model does not contain expressions for horizontal dispersion. In the original model this was unnecessary since the emissions were homogeneous in the entire canyon. In order to model sidewalks or similar segments with zero emission, 
Table 6. Statistical quantities for the south side receptor. Same definitions as in Table 5.

\begin{tabular}{lrrrr}
\hline & & & \multicolumn{2}{c}{ Inhomogeneous emissions } \\
\cline { 4 - 5 } & Measured & $\begin{array}{r}\text { Homogeneous } \\
\text { emissions }\end{array}$ & Exact & Proportional \\
& & 0.83 & 0.84 & 0.84 \\
Correlation coefficient $\left(R^{2}\right)$ & & 0.08 & -0.08 & -0.07 \\
Fractional bias (FB) & & 0.27 & 0.28 & 0.28 \\
Normalised mean square error (NMSE) & 32.7 & 41.2 & 33.1 & 33.6 \\
Annual mean 2007 (ppb) $(\Delta C)$ & 34.5 & 37.2 & 31.0 & 31.0 \\
Annual mean 2008 $(\mathrm{ppb})(\Delta C)$ & 34.6 & 34.5 & 29.1 & 29.2 \\
Annual mean 2009 $(\mathrm{ppb})(\Delta C)$ & &
\end{tabular}
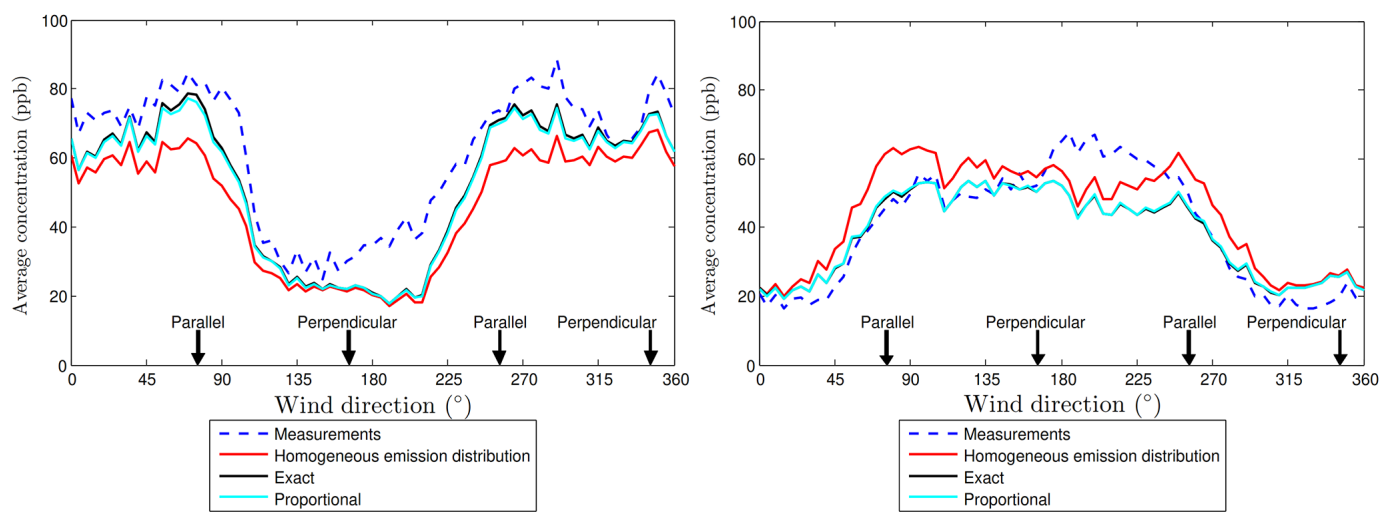

Figure 8. Mean $\mathrm{NO}_{x}$ concentrations as a function of wind direction for the period 2007-2009 for the north side receptor (left side) and the south side receptor (right side). Where the black curve is hardly visible it is identical to the cyan curve.

horizontal dispersion has to be implemented in the model. This is the case due to the geometry of a canyon with zero emission segments on the sides, meaning that as the wind direction approaches parallel, the integration length quickly approaches zero thus leading to zero concentration as illustrated in Fig. 7. Introducing horizontal dispersion in OSPM was however deemed outside the scope of the present study. In the following cases the streets are therefore divided into segments covering both the traffic lanes and the sidewalks. It would be possible to divide the street into more segments to model the individual traffic lanes. However, either the emission of the inner lane had to be distributed over the sidewalk as well, leading to a too low emission density, or the two lanes would have to be of equal width meaning that the segment division would not correspond to the traffic lane division. To avoid these methodological difficulties, it was decided to model the streets as two segments.

\section{Results and discussion}

\subsection{Hornsgatan}

The correlation coefficient $\left(R^{2}\right)$, the fractional bias $(\mathrm{FB})$, and the normalised mean square error (NMSE) for the homogeneous and the exact and proportional inhomogeneous schemes at Hornsgatan for the years 2007-2009 are shown for the north side receptor in Table 5 and for the south side receptor in Table 6.

As can be seen from Tables 5 and 6 , there is a noticeable change in the performance of the model when moving from homogeneous emissions to inhomogeneous emissions, but only very little between the two approaches for modelling inhomogeneous emissions. This confirms the assumption made in Sect. 2.1 that the emission distribution at Hornsgatan is not, to any significant extend, influenced by diurnal variations. It is also noticeable that the increase in performance is especially pronounced for the north side receptor where the FB is markedly improved and the NMSE is improved as well. For the south side receptor a smaller improvement is seen in FB. Conversely, moving from homogeneous emissions to inhomogeneous emissions has almost zero impact on the correlation coefficient on both sides and only a smaller effect on the NMSE on the north side.

The results are, however, confounded by the modelled street level contributions to the concentration's decline whereas the measured concentrations are almost stable. This effect is especially seen on the north side receptor and to a smaller extend on the south side receptor. This effect can most likely be ascribed to the emission model performance, since the effect is time dependent and no interannual change 

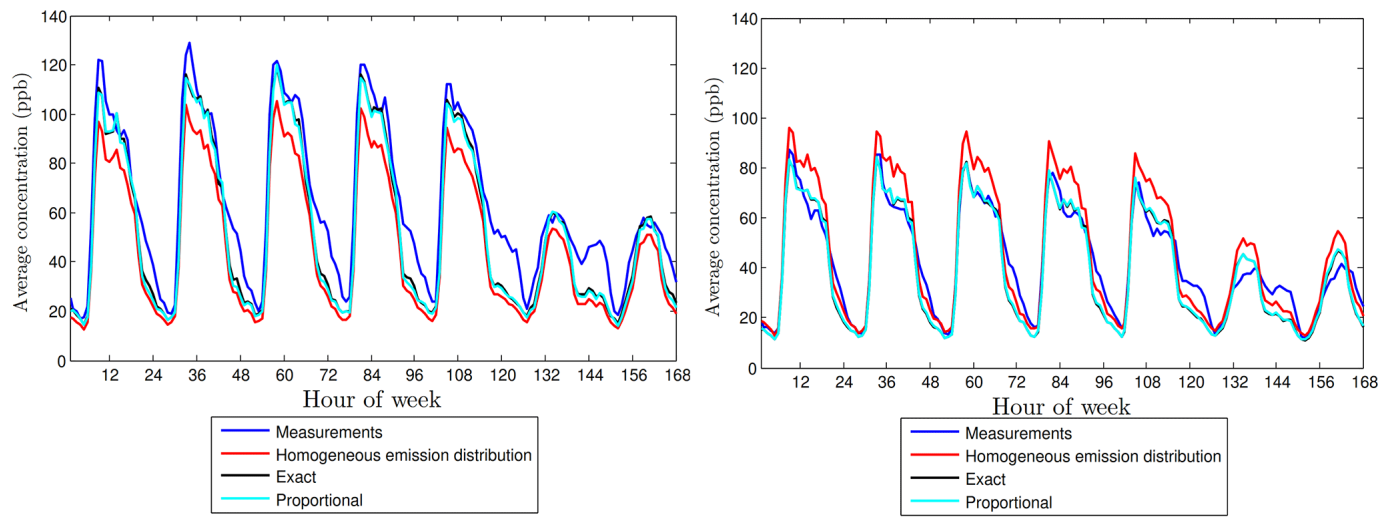

Figure 9. Weekly variation in $\mathrm{NO}_{x}$ concentrations for the period 2007-2009 for the north side receptor (left) and the south side receptor (right). Where the black curve is not visible it is below the cyan curve.
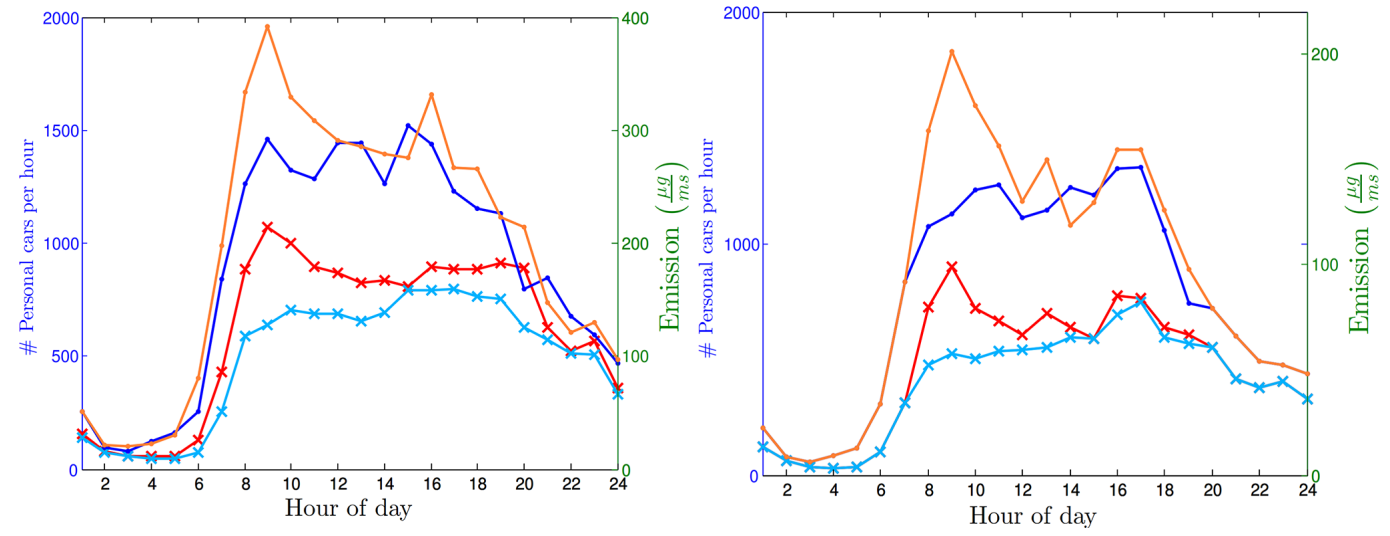

Figure 10. Diurnal variation for weekdays in personal cars per hour and total $\mathrm{NO}_{x}$ emissions for all vehicles for 2003 (left) and 2013 (right). The red and orange graphs are for the northeast direction and the blue graphs are for the southeast direction. The curves marked with dots are the emissions and the curves marked with crosses are the number of personal cars per hour.

in wind speed or direction is found (data not shown). It is most likely that the emission model is predicting too optimistic reductions for the modern Euro 5/6 vehicles that are not obtained under real-world driving conditions as reported in literature (Carslaw et al., 2011). This is also underlined by the fact that the traffic counts from the inductive loop technology matches fairly well with the camera recordings from 2009. The camera recordings were done over 3 months where individual cars were identified and compared with register data (Burman and Johansson, 2010). This means that the total traffic counts must be considered reasonably accurate. Since the vehicle distribution for the year 2009 is known very accurately from the camera recordings, this is probably not the explanation either. This leaves a change in traffic flow situation (levels of service) or a difference between the actual and modelled vehicle fleet - in terms of age composition, emissions as a function of slope, or other factors - over time as possible explanations for this discrepancy.

The wind direction dependency of the concentrations is shown in Fig. 8. As can be seen, the impact of moving from homogeneous emissions to inhomogeneous emissions is largest for parallel wind directions, where each receptor is only exposed to one emission segment. For perpendicular wind directions there is a small difference when the uphill emissions are close to the north side receptor and no difference when it is further away. A similar pattern is seen for the south side receptor with $180^{\circ}$ displacement. The wind direction plot shows a noticeable discrepancy between the model and the measurements around $200^{\circ}$ for both receptors. Gidhagen et al. (2004) state that horizontal dispersion is underestimated in the applied $\kappa-\varepsilon$ CFD model and that this is the cause of this discrepancy. If this is the case the underestimation will also appear in the present wind direction plots due to the lack of horizontal dispersion in OSPM.

The weekly variation in concentrations is shown in Fig. 9. The general diurnal variation plus the difference between weekdays and weekends are reproduced well by the model. As can be seen, the two approaches to inhomogeneous emission modelling are almost indistinguishable. It can also be seen from the figure that the impact of inhomogeneous emis- 

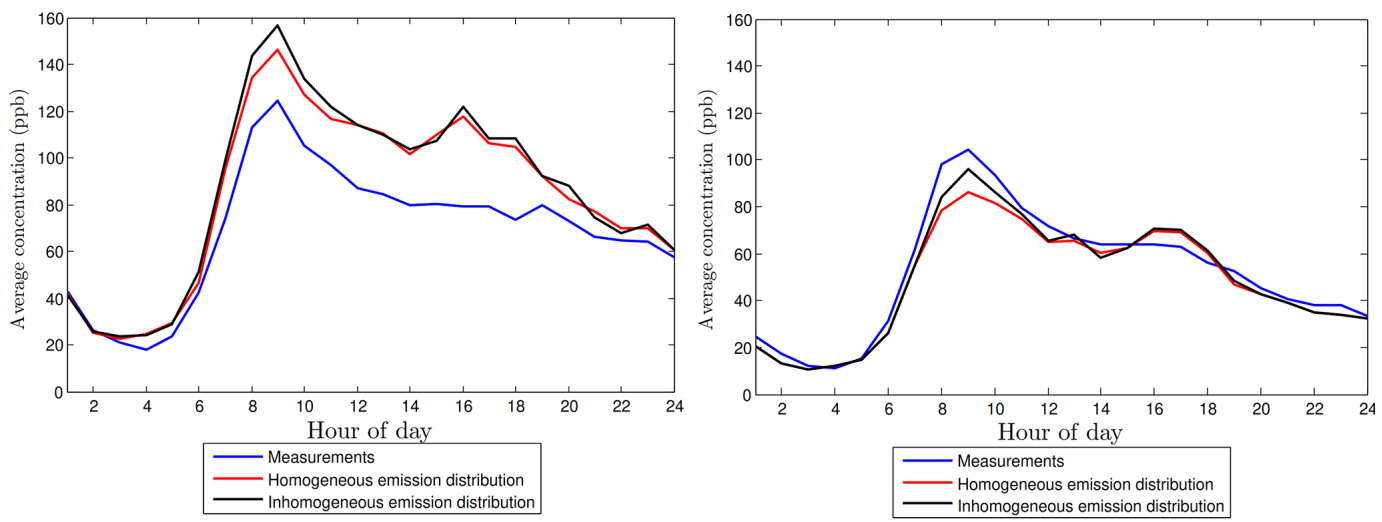

Figure 11. Diurnal variation in $\mathrm{NO}_{x}$ concentrations on weekdays for 2003 (left) and 2013 (right).

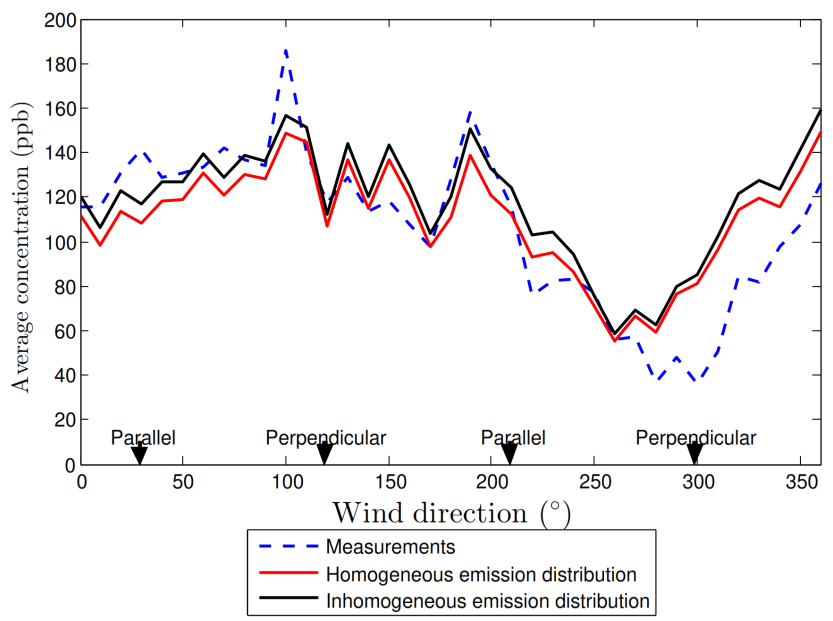

Figure 12. Average $\mathrm{NO}_{x}$ concentrations as a function of wind direction for the morning rush hour 07:00-09:00 LT. for both 2003 and 2013.

sions is largest during the daytime, where the concentrations are largest. Figure 9 shows as well that the diurnal variation is not reproduced in detail. On the north side, the morning rush hours and the evening hours are still underestimated, whereas the night-time concentrations are underestimated. Moreover, the figure indicates a faster diurnal change in the modelled concentrations as compared to the measured concentrations. This probably has to do with the way the traffic flow situation is modelled as four discrete categories, whereas real traffic will behave like a continuum. This is a potential area of improvement for a future study.

Certain times of the week are also clearly wrong, most noticeably Saturday afternoon on the north side receptor and Saturday morning on the south side receptor. This is likewise a potential area of improvement in a future study.

\subsection{Jagtvej}

The diurnal variation in personal cars and emissions for the two driving directions is shown in Fig. 10. As can be seen the emissions follow the variation in personal cars fairly close. The deviations between the variations in emissions and number of cars can be explained by the diurnal variation in heavy duty vehicles. The data show the largest inhomogeneity between north and south directions in the morning rush hour. Moreover, the plots show that the traffic and the corresponding emissions have declined substantially from 2003 to 2013.

The diurnal variations in measured and modelled concentrations for weekdays for the 2 years are shown in Fig. 11. As expected, the change from homogeneous to inhomogeneous emissions only has an influence on the concentrations around rush hour from 08:00 to 09:00 LT, where also traffic is inhomogeneous. However, the difference between the homogeneous and the inhomogeneous emissions is relatively small, approximately $6 \mathrm{ppb}$. As also seen from the graph, the model tends to overestimate the emissions in 2003, whereas the 2013 emissions seem fairly correct. The poor model performance for 2003 has to do with the way the model has previously been calibrated to match the measurements. This means that the emissions used in the present study are markedly different from the emissions used when the model was designed. Adapting the model to the new emissions was deemed outside the scope of the present study and an area of improvement for a future study.

The average concentration as a function of wind direction for the morning rush hour for the 2 years is shown in Fig. 12. As can be seen, the difference between the homogeneous and the inhomogeneous emission is approximately homogeneously distributed among the different wind directions with difference up to $7 \mathrm{ppb}$. When averaging over the 2 years, the emission biases equilibrate each other and give a clearer picture of the wind direction dependency. When looking carefully at the graph it can be seen that the difference in concentration between homogeneous and inhomogeneous emis- 


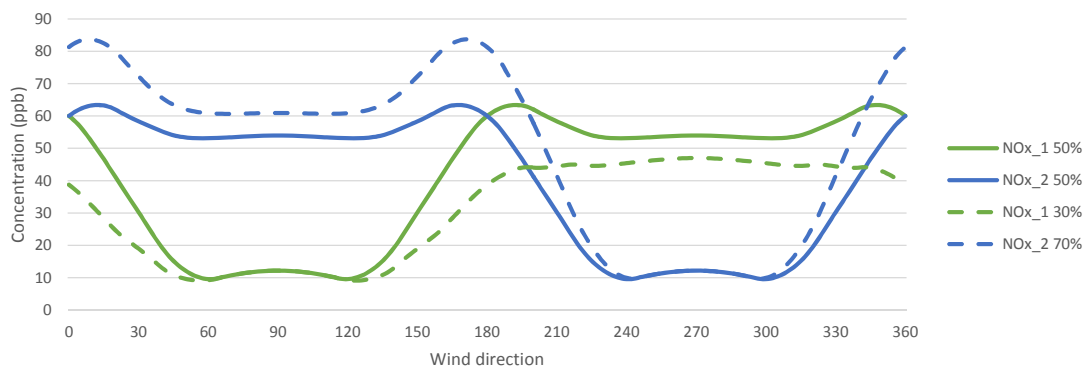

Figure 13. Theoretical calculation of the concentration for the two receptors of a street canyon with two emission segments each covering half the street width and an aspect ratio of one as a function of the emission inhomogeneity and wind direction. Receptor 1 is marked in green and receptor 2 is marked in blue. The inhomogeneity is given as percentages of the total emission for the two segments and the inhomogeneous case is marked with dotted lines.

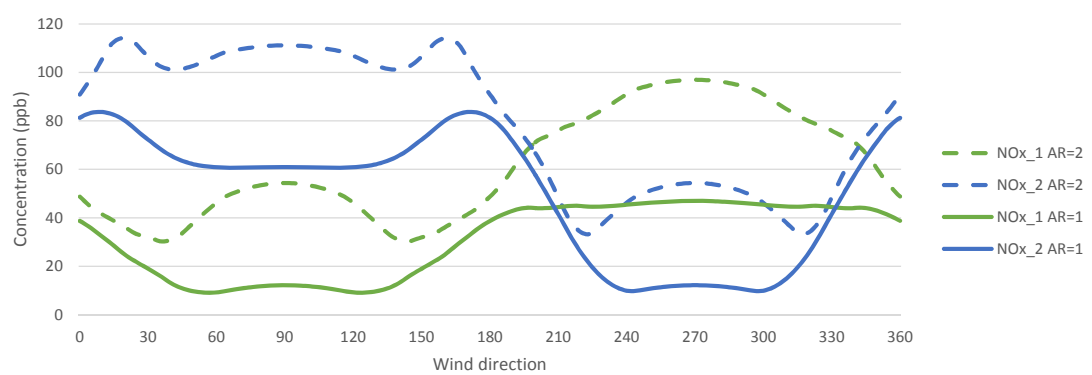

Figure 14. Theoretical calculation of the concentration of the two receptors for a street canyon with an emission inhomogeneity of $70 \%$ (north going)/30\% (south going) as a function of aspect ratio (AR) and wind direction. Receptor 1 is marked in green and receptor 2 is marked in blue. The case with the high aspect ratio is marked with dotted lines.

sions is slightly larger for parallel compared to perpendicular directions. The spike in the measurements around $100^{\circ}$ is likely a result of a random error, since this spike is not seen in the data for the full diurnal cycle (data not shown). Both the homogeneous and the inhomogeneous emission model have difficulties capturing the measurements from approximately 260 to $360^{\circ}$. From 290 to 345 there is an opening in the street canyon and the difficulties of the model to capture this phenomenon was reported in an earlier study (Ottosen et al., 2015). It was thus deemed outside the scope of the present study to develop a solution to this issue as well.

\subsection{Theoretical calculations}

A set of theoretical calculations were performed to clearer illuminate the impact of inhomogeneous emissions without the confounding variables influencing the results of the real street canyons. The calculations are performed with a wind speed of $3.5 \mathrm{~m} \mathrm{~s}^{-1}$, total emissions of $250 \mu \mathrm{g} \mathrm{m}^{-1} \mathrm{~s}^{-1}$, and no urban background concentration. These conditions are corresponding approximately to the average conditions at Hornsgatan. The results of the theoretical analysis of the concentration dependency of the emission inhomogeneity are shown in Fig. 14. As can be seen, a larger emission difference between the two segments also results in a larger difference in concentration. As shown earlier for Hornsgatan, the largest dif- ference is seen for near-parallel wind directions. However, bearing in mind the scale of the $y$ axis, the differences are small. The inhomogeneity at Jagtvej corresponds to approximately $10 \mathrm{ppb}$ and for Hornsgatan to approximately $20 \mathrm{ppb}$, orders of magnitude also confirmed by Figs. 9 and 13. The comparison with measurements will however give a smaller difference, since the real-world data are averages of many different wind speeds and emissions.

The impact of the street canyon aspect ratio on the concentrations resulting from inhomogeneous emissions is shown in Fig. 14. The impact is largest for high aspect ratio (building heights larger than street width) canyons. This is expected, since "the street canyon effect", where the impact of the recirculation zone means larger concentrations for the leeward side compared to the windward side, is larger for high aspect ratio canyons. As such, the impact of inhomogeneous emissions will also be larger for high aspect ratio canyons.

\section{Conclusions}

The present study presented an approach to, and analysed the impact of, implementation of inhomogeneous emissions in a semi-parameterized street canyon model (OSPM). The results were validated against two real-world data sets: one being inhomogeneous as a result of the slope of the street 
and the other as a result of inhomogeneous directional traffic during rush hours. Moreover, the impacts of emission inhomogeneity and street aspect ratio were analysed theoretically.

The results showed that the model including inhomogeneous emissions was better able to reproduce the measured values on the two real-world streets. The impact of the inhomogeneous emissions was largest for the sloping street and the largest effect was seen for near-parallel wind directions. The results for both streets were however influenced by other factors as well, most likely uncertainties in the emissions, which led to less clarity in the results. Overall the adoption of inhomogeneous emissions leads to a performance increase of up to $15 \%$ in fractional bias at the north side receptor of Hornsgatan and a difference in street level contribution of up to $8 \mathrm{ppb}$. For Jagtvej the difference was shown to be up to $7 \mathrm{ppb}$ in the morning rush hour.

\section{Future work}

The present study showed a potential for obtaining an improvement in model performance by introducing inhomogeneous emissions in models like OSPM. Two model elements are of immediate interest in relation to the present work.

- At present the receptor is located on the wall of the street. In reality, measurement stations are often located several metres from the wall leading to a shorter dilution of the emissions and thereby a higher concentration. Being able to move the receptor freely in the cross-canyon direction could potentially lead to a model performance improvement.

- At present the model does not facilitate the inclusion of zero emission segments such as pedestrian areas. As described in Sect. 3.2, this means that an accurate description of a road like Hornsgatan, where traffic counts exist for all four lanes, is not yet possible. Introducing horizontal dispersion in the model will thus potentially make it possible to describe streets like Hornsgatan more accurately.

\section{Code availability}

Name of the software: WinOSPM (Windows version of the Operational Street Pollution Model, OSPM).

Developer: Department of Environmental Science (ENVS), Aarhus University, Denmark.

Contact address: Aarhus University, Department of Environmental Science Frederiksborgvej 399, 4000 Roskilde, Denmark.

E-mail: ospm@au.dk

Operational System: Microsoft Windows 7 or later.

Software requirements: None.

Hardware requirements: At least $100 \mathrm{Mb}$ free hard drive space and $1 \mathrm{~Gb}$ RAM.
Programming language: Visual Basic 6 combined with linked libraries written in Fortran 77.

Availability and cost: WinOSPM is a commercial software requiring licensing. Information on the actual licensing conditions is given at www.au.dk/OSPM. A fully functioning 100-day evaluation version can be freely downloaded from this site.

Author contributions. T.-B. Ottosen, M. Ketzel, K. E. Kakosimos, C. Johansson, R. Berkowicz, O. Hertel, and J. Brandt participated in setting up the study concept and the study design was done by T.-B. Ottosen, M. Ketzel, K. E. Kakosimos, C. Johansson, and R. Berkowicz. T.-B. Ottosen did the implementation of inhomogeneous emissions in OSPM with input from M. Ketzel and K. E. Kakosimos. T.-B. Ottosen conducted the data analysis with contributions to analysis and interpretation from M. Ketzel, K. E. Kakosimos, and C. Johansson. C. Johansson furthermore provided access to data from Hornsgatan and T. Ellermann provided access to data for Jagtvej. S. S. Jensen provided input on the traffic profile for Jagtvej. H. Skov and K. E. Kakosimos obtained funding for the study. T.-B. Ottosen wrote the article manuscript. All the co-authors participated in the interpretation of the results, provided critical comments to the manuscript, and read and approved the final manuscript.

Acknowledgements. This publication was made possible by a NPRP award [NPRP 7-674-2-252] from the Qatar National Research Fund (a member of The Qatar Foundation). The statements made herein are solely the responsibility of the authors.

The HPC (High Performance Computing) resources and services used in this work were provided by the IT Research Computing group in Texas A\&M University at Qatar. IT Research Computing is funded by the Qatar Foundation for Education, Science and Community Development (http://www.qf.org.qa).

Edited by: A. Kerkweg

\section{References}

Assael, M. J., Delaki, M., and Kakosimos, K. E.: Applying the OSPM model to the calculation of $\mathrm{PM}_{10}$ concentration levels in the historical centre of the city of Thessaloniki, Atmos. Environ., 42, 65-77, 2008.

Berkowicz, R., Palmgren, F., Hertel, O., and Vignati, E.: Using measurements of air pollution in streets for evaluiation of urban air quality - meteorological analysis and model calculations, Sci. Total Environ., 189/190, 259-265, 1996.

Berkowicz, R., Hertel, O., Larsen, S. E., Sørensen, N. N., and Nielsen, M.: Modelling traffic pollution in streets, Ministry of Environment and Energy, National Environmental Research Institute, Roskilde, Denmark, available at: http://www2.dmu. $\mathrm{dk} / 1$ _viden/2_Miljoe-tilstand/3_luft/4_spredningsmodeller/5_ OSPM/5_description/ModellingTrafficPollution_report.pdf (last access: October 2015), 1997. 
Berkowicz, R., Winther, M., and Ketzel, M.: Traffic pollution modelling and emission data, Environ. Model. Softw., 21, 454-460, 2006.

Boulter, P. and McCrae, I.: Assessment and reliability of transport emission models and inventory systems, TRL Limited, available at: http://www.trl.co.uk/reports-publications/ trl-reports/report/?reportid=6413 (last access: October 2015), 2007.

Burman, L. and Johansson, C.: Utsläpp och halter av kväveoxider och kvävedioxid på Hornsgatan, Environment and Health Administration, SLB-analys, Stockholm, Sweden, 2010.

Carslaw, D. C., Beevers, S. D., Tate, J. E., Westmoreland, E. J., and Williams, M. L.: Recent evidence concerning higher $\mathrm{NO}_{x}$ emissions from passenger cars and light duty vehicles, Atmos. Environ., 45, 7053-7063, 2011.

Denby, B. R., Sundvor, I., Johansson, C., Pirjola, L., Ketzel, M., Norman, M., Kupiainen, K., Gustafsson, M., Blomqvist, G., Kauhaniemi, M., and Omstedt, G.: A coupled road dust and surface moisture model to predict non-exhaust road traffic induced particle emissions (NORTRIP). Part 2: Surface moisture and salt impact modelling, Atmos. Environ., 81, 485-503, 2013a.

Denby, B. R., Sundvor, I., Johansson, C., Pirjola, L., Ketzel, M., Norman, M., Kupiainen, K., Gustafsson, M., Blomqvist, G., and Omstedt, G.: A coupled road dust and surface moisture model to predict non-exhaust road traffic induced particle emissions (NORTRIP). Part 1: Road dust loading and suspension modelling, Atmos. Environ., 77, 283-300, 2013b.

EEA: EMEP/CORINAIR Atmospheric Emissions Inventory Guidebook, Chapter on Exhaust Emissions from Road Transport. Methodology for COPERT 4., European Environmental Agency, 2009.

Ellermann, T., Nøjgaard, J. K., Nordstrøm, C., Brandt, J., Christensen, J., Ketzel, M., Jansen, S., Massling, A., and Jensen, S. S.: The Danish Air Quality Monitoring Programme - Annual Summary for 2012, Arhus University, DCE - Danish Centre for Environment and Energy, 2013.

Ghenu, A., Rosant, J.-M., and Sini, J.-F.: Dispersion of pollutants and estimation of emissions in a street canyon in Rouen, France, Environ. Model. Softw., 23, 314-321, 2008.

Gidhagen, L., Johansson, C., Langner, J., and Olivares, G.: Simulation of $\mathrm{NO}_{x}$ and ultrafine particles in a street canyon in Stockholm, Sweden, Atmos. Environ., 38, 2029-2044, 2004.

Gokhale, S. B., Rebours, A., and Pavageau, M.: The performance evaluation of WinOSPM model for urban street canyons of Nantes in France, Environ. Monit. Assess., 100, 153-176, 2005.

Hertel, O. and Berkowicz, R.: Modelling Pollution from Traffic in a Street Canyon, Evaluation of Data and Model Development, National Environmental Research Institute, Roskilde, Denmark, 1989.

Hertel, O., Hvidberg, M., Ketzel, M., Storm, L., and Stausgaard, L.: A proper choice of route significantly reduced air pollution exposure - A study on bicycle and bus trips in urban streets, Sci. Total Environ., 389, 58-70, 2008.

Johansson, C., Norman, M., and Burman, L.: Road traffic emission factors for heavy metals, Atmos. Environ., 43, 4681-4688, 2009.

Kakosimos, K. E., Hertel, O., Ketzel, M., and Berkowicz, R.: Operational Street Pollution Model OSPM) - a review of performed application and validation studies, and future prospects, Environ. Chem., 7, 485-503, 2010.
Kean, A. J., Harley, R. A., and Kendall, G. R.: Effects of Vehicle Speed and Engine Load on Motor Vehicle Emissions, Environ. Sci. Technol., 37, 3739-3746, 2003.

Ketzel, M., Omstedt, G., Johansson, C., Düring, I., Pohjola, M., Oettl, D., Gidhagen, L., Wåhlin, P., Lohmeyer, A., Haakana, M., and Berkowicz, R.: Estimation and validation of $\mathrm{PM}_{2.5} / \mathrm{PM}_{10}$ exhaust and non-exhaust emission factors for practical street pollution modelling, Atmos. Environ., 41, 9370-9385, 2007.

Ketzel, M., Berkowicz, R., Hvidberg, M., Jensen, S. S., and Raaschou-Nielsen, O.: Evaluation of AirGIS: A GIS-based air pollution and human exposure modelling system, Int. J. Environ. Pollut., 47, 226-238, 2011.

Ketzel, M., Jensen, S. S., Brandt, J., Ellermann, T., Olesen, H. R., Berkowicz, R., and Hertel, O.: Evaluation of the Street Pollution Model OSPM for Measurements at 12 Streets Stations Using a Newly Developed and Freely Available Evaluation Tool, J. Civil Environ. Eng., S:1004, doi:10.4172/2165-784X.S1-004, 2012.

Ketzel, M., Hertel, O., Ottosen, T.-B., Kakosimos, K., and Berkowicz, R.: Validation of New Parameterisations for the Operational Street Pollution Model (OSPM), in: Proceedings of Abstracts 9th International Conference on Air Quality - Science and Application, University of Hertfordshire, Hatfield, UK, 2014.

Kukkonen, J., Valkonen, E., Walden, J., Koskentalo, T., Karppinen, A., Berkowicz, R., and Kartastenpää, R.: Measurements and modelling of air pollution in a street canyon in Helsinki, Environ. Monit. Assess., 65, 371-379, 2000.

Larssen, S., Mellios, G., van den Hout, D., Kalognomou, E. A., and Moussiopoulos, N.: Street Emission Ceiling (SEC) exercise - Phase 3 report, European Topic Centre on Air and Climate Change, available at: http://acm.eionet.europa.eu/reports/ ETCACC_TechnPaper_2006_7_SEC_phase3 (last access: October 2015), 2007.

Moussiopoulos, N., Kalognomou, E. A., Samaras, Z., Mellios, G., Larssen, S. E., Gjerstad, K. I., de Leeuw, F. A. A. M., van den Hout, K. D., and Teeuwisse, S.: Street Emission Ceiling exercise - Phase 1 report, European Topic Centre on Air and Climate Change, available at: http://acm.eionet.europa.eu/ docs/ETCACC_TechnPaper2003_11_SEC_Phase1Rep.pdf (last access: October 2015), 2004.

Moussiopoulos, N., Kalognomou, E. A., Papathanasiou, A., Eleftheriadou, S., Barmpas, Ph., Vlachokostas, Ch., Samaras, Z., Mellios, G., Vouitsis, I., Larssen, S. E., Gjerstad, K. I., de Leeuw, F. A. A. M., van den Hout, K. D., Teeuwisse, S., and van Aalst, R.: Street Emission Ceiling exercise - Phase 2 report, European Topic Centre on Air and Climate Change, http://acm.eionet.europa.eu/docs/ETCACC_ TechnPaper_2004_5_SEC_Phase2Rep.pdf (last access: October 2015), 2005.

Olivares, G., Johansson, C., Ström, J., and Hansson, H.-C.: The role of ambient temperature for particle number concentrations in a street canyon, Atmos. Environ., 41, 2145-2155, 2007.

Ottosen, T.-B., Ketzel, M., Skov, H., Hertel, O., Brandt, J., and Kakosimos, K.: A Parameter Estimation and Identifiability Analysis Methodology Applied to a Street Canyon Air Pollution Model, Environ. Model. Softw., submitted, 2015.

Silver, J. D., Ketzel, M., and Brandt, J.: Dynamic parameter estimation for a street canyon air quality model, Environ. Model. Softw., 47, 235-252, 2013. 
TetraPlan A/S: Standardværdier for trafikdata til OSPM modellen, TetraPlan A/S, Copenhagen, Denmark, 2001.

Vardoulakis, S., Gonzales-Flesca, N., Fisher, B. E. A., and Pericleous, K.: Spatial variability of air pollution in the vicinity of a permanent station in central Paris, Atmos. Environ., 39, 27252736, 2005.
Vardoulakis, S., Valiantis, M., Milner, J., and ApSimon, H.: Operational air pollution modelling in the UK - Street canyon applications and challenges, Atmos. Environ., 41, 4622-4637, 2007.

Vägverket and SMHI: Dokumentation ARTEMIS i SIMAIR, Vägverket och SMHI, Stokholm, Sweden, 2007. 